\title{
Effect of Soaking Time in Sodium Metabisulfite Solution on the Physicochemical and Functional Properties of Durian Seed Flour
}

\author{
Andri Kumoro ${ }^{1 *}$ and Jefri Hidayat ${ }^{2}$ \\ ${ }^{1}$ Department of Chemical Engineering, Faculty of Engineering, Diponegoro University, Semarang, Indonesia \\ ${ }^{2}$ Master of Chemical Engineering Study Program, Faculty of Engineering, Diponegoro University, Semarang, Indonesia
}

\begin{abstract}
With regard to its high carbohydrate and gum contents, durian seed flour has been used as a substitute to wheat flour in butter cake and cookies manufactures. Unfortunately, processing of fruit seeds into flour may be hampered by discoloration, which may affect the nutrition and sensory quality of the food products. The objective of this study is to investigate the effect of soaking time on the physicochemical and functional properties of durian seed flour. Durian seed chips were soaked in $0.6 \% \mathrm{w} / \mathrm{v}$ sodium metabisulfite solution as anti-browning agent at $30^{\circ} \mathrm{C}$ for desired periods $\left(40,60,80,100,120\right.$ minutes), followed by drying at $50^{\circ} \mathrm{C}$ for 17 hours, milling and sieving to obtain flour. The flour was analyzed for its moisture, ash, protein, fat and carbohydrate contents, sulfite residue, yield, gelatinization temperature, and water and oil absorption capacities (WAC and OAC). The results showed that longer soaking time reduced the moisture and ash content of durian seed flour, but increased most of the other studied parameters. The WAC, OAC and fat content were less affected by soaking time. It can be concluded that soaking of durian seed chips in sodium metabisulfite solution can improve the nutrition and functional properties of flour. Based on the residual sulfite content, durian seed flour obtained in this work is safe for consumption.
\end{abstract}

\section{Introduction}

Wheat flour has been used for production of noodle and baked products such as breads, cakes, biscuits, and cookies for centuries. This is due to the unique nature and functional properties of wheat flour proteins called gluten [1]. However, wheat cannot be commercially cultivated in the tropical countries such as Indonesia and Malaysia mainly due to climate differences. In order to cover the domestic demand, Indonesia imported wheat flour amounted 97,830 tons or equivalent to US\$33,963 in 2015 as a reason for the diversification of food products $[2,3]$. Unfortunately, individuals with celiac disease may often experience adverse reactions to products containing gluten. Larrosa et al. suggested that the elimination of gluten from food products can be done by substitution of wheat flour with specific materials with closely similar physicochemical properties to gluten [4].

Durian (Durio zibethinus Murr.) is one of the seasonal fruits in South East Asia and popularly known as The King of Fruits. Thailand, Indonesia, Malaysia and the Philippines are the major producers of durian [5]. In 2013, production of durian in Indonesia was approximately $1,818,949$ tons and still increased after year [6]. The fruit pulp has a unique taste and strong smell. It is usually eaten fresh or processed into ice cream, pancake and various traditional foods [7]. The edible portion of durian fruit is only about $30-35 \%$ of its total weight, whereas the seeds $(20-25 \%)$ and the shell are usually disposed. It is clear that, the durian seed as by-product of durian fruit production can reach 454,737 tons per year, but it has not been fully utilized. Ripe durian seeds contain $51.1 \%$ moisture, $43.6 \%$ carbohydrates, dietary fiber, polysaccharide gum (20$25 \% \mathrm{w} / \mathrm{w})$, and protein $(3-5 \% \mathrm{w} / \mathrm{w})$ [8-9]. The carbohydrate content of whole and dehulled durian seed flour is $73.90 \%$ and $76.8 \%$, respectively [10]. The amylose content of durian seed is $22.76 \%$ [11]. Hence, it gives a great potential to substitute the consumption of wheat flour as much as $10.1 \%$ with the yield of durian flour by $60 \%$. Unfortunately, the seed also contains cyclopropene fatty acids, namely sterculic acid, dihydrosterculic acid and malvalic acid which may cause shortness of breath as well as cancer in rainbow trout [12] and aortic atherosclerosis in rabbit [13]. Therefore, durian seeds are toxic while consumed raw. Thermal cooking, such as boiling, steaming, burning and roasting were reported to reduce the

Corresponding author: andreykomoro@che.undip.ac.id 
toxicity of the seed and made them safe for consumption [14].

The color intensity is one of the main important factors influencing the appearance and overall acceptability of food products. In order to substitute wheat flour, durian seed flour must have minimum 92.5\% lightness [15]. The problem in making durian seed flour is lack of lightness due to the accumulation of brown pigment resulting from non-enzymatic and enzymatic reactions. Sulfite has been used as antibrowning agent because it is a strong inhibitor of polyphenol oxidases and peroxidases, which may inhibit enzymatic and non-enzymatic browning in fruits and vegetables [16]. The objective of this study is to investigate the effect of time on the prevention of browning through soaking durian seed chips in sodium metabisulfite solution by evaluating physicochemical and functional properties of durian seed flour.

\section{Material and Methods}

\subsection{Material}

In this study, durian (Durio zibethinus Murr.) seed as by-product of durian fruit was collected from durian farmers in Gunungpati, Semarang, Indonesia. Sodium metabisulfite as an anti-browning agent and other chemical reagents for analyses were purchased from an authorized chemicals distributor in Semarang.

\subsection{Making of durian seed flour and Browning Investigation}

Durian seed flour was produced based on the method developed by Chowdhury et al. with some modification [17]. Matured durian seeds were washed thoroughly and peeled to remove outer seed coat and pericarp. Subsequently, they were sliced into small size of $2 \mathrm{~cm} \times 2 \mathrm{~cm} \times 1 \mathrm{~cm}$ and were soaked immediately in sodium metabisulfite solution with $0.6 \%$ w/v concentration at $30^{\circ} \mathrm{C}$ for $40,60,80,100$, and 120 minutes. The durian seeds were then drained and oven dried at $50^{\circ} \mathrm{C}$ for 17 hours. To obtain durian seed flour, the dried chips were milled and passed through 80 mesh sieves. Ultimately, the flour was collected and stored in plastic containers at around $8^{\circ} \mathrm{C}$ till further use. A control durian seed flour sample was prepared from durian seeds without soaking in sodium metabisulfite solution. Flour yield was calculated as the percentage ratio between mass of durian seed flour and initial mass of durian seed.

\subsection{Physicochemical analysis of flour}

\subsubsection{Chemical analysis}

Proximate composition of the durian seed flour representative samples were analyzed for crude protein, fat, ash and moisture content according to standard methods of AOAC [18]. The total carbohydrate was calculated by the difference [19]. Sulfite residue was determined by iodometric titration method prescribed in American Public Health Association [20]. All of the analyses were carried out in triplicates and the reported values were the average of each measurement.

\subsubsection{Physical analysis}

Gelatinization temperature was determined by differential scanning calorimetry method as previously used by Coral et al. [21]. The whiteness of durian seed flours were measured by using a Chroma Meter (Minolta Type CR-300, Japan) and considered the parameters L from 0 for black to 100 for white [1].

\subsubsection{Functional properties analysis}

Water absorption capacity (WAC) was examined according to the methods used by Niba et al. [22] and was reported as percentage of volume of water per mass of flour sample. Oil absorption capacity (OAC) was evaluated according to the method developed by Sosulski et al. and was expressed as percentage of mass of oil absorbed per mass of flour sample [23].

\section{Results and Discussion}

\subsection{Chemical properties of durian seed flours}

Soaking of durian seed chips in sodium metabisulfite solution was mainly expected to prevent the seeds from browning. However, some metabolic reactions can take place during soaking, altering the content of some components in the flour obtained [24]. This effect varied with botanical sources and soaking conditions such as type of soaking solutions, soaking period and temperature [25]. The chemical composition of durian seed flours obtained in this work are presented in Table 1.

Table 1. Chemical properties of durian seed flour

\begin{tabular}{ccccccc}
\hline Chemical properties & \multicolumn{6}{c}{ Soaking time (minutes) } \\
\cline { 2 - 7 } & 0 & 40 & 60 & 80 & 100 & 120 \\
\hline Moisture (\%) & 9.18 & 8.27 & 7.62 & 6.35 & 4.78 & 5.17 \\
Ash (\%) & 3.25 & 3.22 & 3.07 & 2.76 & 2.52 & 2.21 \\
Fat (\%) & 0.64 & 0.91 & 0.45 & 0.73 & 0.64 & 0.91 \\
Protein (\%) & 6.30 & 6.34 & 6.84 & 7.12 & 7.42 & 8.24 \\
Carbohydrate (\%) & 75.90 & 81.26 & 81.99 & 83.04 & 84.64 & 83.47 \\
Sulfur residue (ppm) & 0 & 23.12 & 37.45 & 50.34 & 85.71 & 102.56 \\
\hline \multicolumn{7}{|c}{} \\
\hline The values are expressed as the mean of triplicates.
\end{tabular}

Moisture content of the durian seed flour decreased significantly as the soaking time increased. This result could be attributed to the effect of sulfites in degrading the seed cells tissue, resulting in larger pore sizes on the cut surface and facilitating easy removal of moisture through internal diffusion and evaporation during drying of samples [26-27]. Low moisture content means low water activity and is an indication of longer shelf life [28]. Similarly, the creation of larger pores induced leaching of minerals from the inner pores to the outside pores of the seed chips and finally to the soaking solution, which caused reduction of ash content in the durian seed flours. Fat content of durian seed flours did not change significantly with the 
increase of soaking time. However, no regular pattern of the change was observed.

In contrast to the above findings, the protein and carbohydrate content of durian seed flours increased with soaking time. Rom et al. [26] reported that protein bodies did not change during soaking in sodium metabisulfite solution suggesting no protein degradation during this process. Therefore, the increase in protein carbohydrate content may likely be the result of reduction of moisture and ash contents. Unfortunately, the protein content of the durian seed flours were only about half of that of commercial wheat flour. This fact suggests that the durian seed flour is not suitable for use in bread making; however, it could be suitable for making cookies or cakes [10].

In general, the chemical properties of durian seed flour obtained in this work are comparable to that reported in the literature [10]. The differences are more likely to be caused by treatment and processing method, type or cultivar, maturity and cultivation method.

As expected, the residual sulfite content increased as the durian seed chips were soaked in sodium metabisulfite solution for longer time. Longer contact time between durian seed chips and sodium metabisulfite solution let the sulfite to penetrate the durian seed chips more extensively and promote the reaction to proceed. However, some of the entrapped sulfite may be left in the durian seed chips after the drying process. The maximum level of sulfite is changeable for different products, such as crustaceous $50 \mathrm{mg} / \mathrm{kg}$, meat products $450 \mathrm{mg} / \mathrm{kg}$, dry biscuit between 30 and $50 \mathrm{mg} / \mathrm{kg}$, vegetables between 50 and $2000 \mathrm{mg} / \mathrm{kg}$ and beverages between 20 and 2,000 $\mathrm{mg} / \mathrm{kg}$ [29]. In particular, the General Standards for Food Additives (GSFA) Codex has set the maximum permissible level (MPL) for sulfites in starch and flour as food ingredients as $200 \mathrm{mg} / \mathrm{kg}$. It is obvious that the residual sulfur in all of the durian seed flours obtained in this work were still in acceptable level. Therefore, the treatment of durian seed chips to produce durian seed flour using sodium metabisulfite solution is safe and the durian seed flours can be used to manufacture bakery products.

Sulfite residue is not the only parameter of food safety. The harmful condition may also come from the compounds originally contained in the food sources. Therefore, extensive investigations on the cyclopropene fatty acids content as the toxic sompound in durian seed flour obtained in this research is still need to be conducted to ensure the safety of its long term consumption.

\subsection{Physical properties of durian seed flours}

The appearance of durian seed flours obtained from sodium metabisulfite pre-soaked and native durian seed chips are shown in Fig. 1, while the yield and physical properties of durian seed flour are presented in Table 2.

It can be visually observed in Fig. 1 that as the soaking time increased, the durian seed flours obtained are brighter. Bleaching process associated with prevention of the formation of melanoidin compound from the reaction between sulfite and carbonyl group in durian seed flour. Hence, the flours obtained from presoaked durian seed chips in sodium metabisulfite solution at longer time exhibited brighter color than that of control sample. The color analysis also revealed that the lightness of durian seed flours increased from 65 to 80 as shown in Table 2. Sodium metabisulfite has played its role as inhibitor of polyophenol oxidases (PPO) and peroxidases and therefore inhibit enzymatic and non-enzymatic browning in durian seed flours [16]. Lambrecht explained that sulfites react with PPO itself, and thus irreversibly inhibiting PPO by modifying the protein structure [30]. Since the lightness of durian seed flours are still below the acceptable value [15], they are still unsuitable for use as substitute to wheat flour.
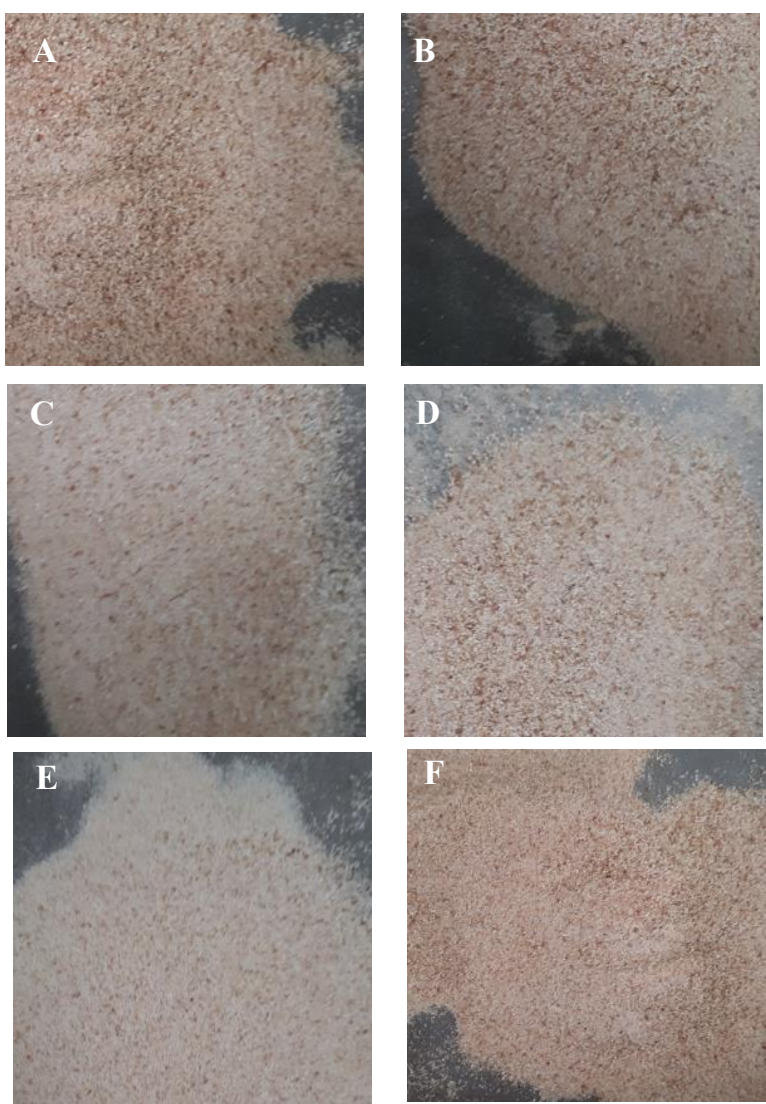

Fig. 1. Visual appearance of durian seed flours

Table 2. Physical properties of durian seed flour

\begin{tabular}{ccccccc}
\hline Physical & \multicolumn{5}{c}{ Soaking time (minutes) } \\
\cline { 2 - 7 } properties & 0 & 40 & 60 & 80 & 100 & 120 \\
\hline Y (\%) & 50.12 & 50.52 & 49.25 & 50.67 & 51.53 & 52.97 \\
GT (\%) & 56.91 & 58.22 & 60.54 & 62.17 & 65.21 & 70.89 \\
W (L) & 65 & 70 & 71 & 73 & 75 & 80 \\
WAC (\%) & 145.62 & 147.45 & 148.17 & 149.33 & 150.28 & 151.77 \\
OAC (\%) & 24 & 28 & 27 & 27 & 26 & 25 \\
\hline
\end{tabular}

$\mathrm{Y}=$ yield, $\mathrm{GT}=$ gelatinization temperature, $\mathrm{W}=$ whiteness, $\mathrm{WAC}=$ water absorption capacity, $\mathrm{OAC}=$ oil absorption capacity. The values are expressed as the mean of triplicates.

Furthermore, the durian seed flour yields ranged from $49.25 \%$ to $52.97 \%$, which is consistent with the literature that fresh durian seeds may contain $51.1 \%$ 
moisture and the rest being dry matters [8]. It is likely that only very little dry matters were leached out from the durian seed chips during soaking in sodium metabisulfite solution.

The temperature at which gelatinization of starch take place is called as the gelatinization temperature [31]. Generally, the flour which was higher in starch content required lower temperature for gelatinization [32]. Table 2 indicates that the durian seed flours obtained from soaking of durian seed chips in sodium metabisulfite solution at longer time exhibited higher gelatinization temperature. Gelatinization temperature of starch depends on some parameters, which include moisture content, lipid content, heating rate, process applied to starch before gelatinization and amylose/amylopectin ratio of starch [33].

Gelatinization process is not only followed by carbohydrate level due to amylose and amylopectin molecule, but also water absorption which is inside pore gain more water [23]. With lower moisture content and highly porous microstructure the durian seed flour obtained from longer soaking time may adsorb more water. The starch granules become extraordinarily swollen and not necessarily return to their original state. Since carbohydrate and water absorption is getting higher, and then the gelatinization temperature will be higher.

\subsection{Functional properties of durian seed flours}

Water absorption capacity (WAC) represent the ability of a product to associate with water under conditions where water is limited and assure product cohesiveness $[34,35]$. Table 2 shows that WAC of durian seed flours increased as the soaking time increased. A higher WAC value of flour could be attributed to the presence of higher amount of carbohydrates [36]. The other components, such as fiber, protein and amylose content are also the main factors that may influence WAC value [32]. The higher protein content lead to strong hydrogen bond, which subsequently increase the WAC of durian seed flour [37].

The oil absorption capacity (OAC) is the ability of the dry starch to physically bind fat by capillary attraction and it is of great importance that makes the flour suitable in promoting improvement in flavor and mouth feel when used in food preparation $[32,38]$. The $\mathrm{OAC}$ of durian seed flour increased when the durian seed chips were soaked in sodium metabisulfite solution for 40 minutes to a maximum value, but then leveled off at longer soaking time. Both the protein content and the type contribute to the oil-retaining properties of food materials [39]. Non-polar amino acid side chains of protein can form hydrophobic interaction with hydrocarbon chains of lipid and has implication in functional properties of durian seed flour [40]. Therefore, the lower OAC of flour might be due to lower content hydrophobic proteins which show superior binding of lipids [41]. However, the OAC values obtained in this work did not correspond with the protein content of the respective soaking conditions.

\section{Conclusion}

The effect of sodium metabisulfite soaking time on physicochemical properties of durian seeds flour has been studied. Soaking of durian seed chips in sodium metabisulfite solution significantly altered the nutrition content, except fat content. This process also changed the whiteness, gelatinization temperature, water absorption capacity and oil absorption capacity of durian seed flour. The residual sulfite levels were varied from 0 to $102.56 \mathrm{ppm}$. Based on the residual sulfite level, the durian seed flours obtained are safe for consumption, mainly in the manufacture of butter cake and cookies.

\section{Acknowlegdement}

The authors are grateful to dr. Niluh Putu Ratih Restiti for financial support and Chemical Engineering Department, Diponegoro University, Semarang for providing research facilities.

\section{References}

1. N. Tharise. E. Julianti, M. Nurminah, Int. Food Res. J. 4,1641-1649 (2014)

2. Bizteka, Perkembangan Impor Tepung Terigu (PT. Citra Cendekia Indonesia, 2016)

3. A. Amin, A. Ahmad, Y. Yin-Yin, N. Yahya, N. Ibrahim, Food Hydrocol. 21, 273-279 (2006)

4. V. Larrosa, G. Lorenzo, N. Zaritzky, A. Califano, J. Food Sci. 57, 520-526 (2013)

5. F. Azima, T. Anggraini, D. Syukri, A. Septia, Pak. J. Nutr., 3, 175-178 (2017)

6. Statistics Indonesia, Fruits Production by Province (Ton) (Statistics Indonesia, Jakarta, 2014)

7. S. Ketsa, T. Daengkanit, J. Sci. Hortic., 80, 181188 (1999)

8. M. J. Brown, Durio - A Bibliographic Review (International Plant Genetic Resources Institute, New Delhi, India, 1997).

9. H. Mirhosseini, B. Tabatabaee Amid, Chem. Cent. J. 7, 1-7 (2013)

10. A. M. Amin, R. Arshad, Int. J. Postharvest Technol. Innovation, 1, 367-375 (2009)

11. T. Tongdang, Starch/Starke 6, 199-207 (2008)

12. R. O. Sinnhuber, J. D. Hendricks, G. B. Putnam, J. H. Wales, N. E. Pawlowski, J. E. Nixon, D. J. Lee, Fed. Proc. (Abs.) 35, 1652 (1976).

13. T. L. Ferguson, J. H. Wales, R. O. Sinnhuber, D. J. Lee, Food Cosmet. Toxicol. 14, 15 (1976)

14. S .K. Berry, Lipids 15, 452-255 (1979)

15. Wheat Associates, Wheat and Flour Testing Methods: A Guide to Understanding Wheat and Flour Quality (Wheat Marketing Center Inc., Portland, Oregon, USA, 2007) 
16. A. M. Y. Brown, Understanding Food: Principles and Preparation (Wadsworth, Thomson Learning Inc., Singapore, 2005)

17. A. Chowdhury, A. Bhattacharyya, P. Chattopadhyay, Indian J. Nat. Prod. Resour. 3, 347-353 (2012)

18. AOAC, Official Methods of Analysis (Washington, D. C., 1990)

19. G. Winarno, Kimia Pangan dan Gizi (PT. Gramedia Pustaka Utama, Jakarta, 1995)

20. S. Clesceri, E. Greenberg, D. Eaton, Standard Methods for the Examination of Water and Wastewater (APHA American Public Health Association, 1998)

21. D. F. Coral, P. Pineda-Gomez, A. Rosales-Rivera, M. E. Rodriguez-Garcia, J. Physc. Conf. Ser. 167, 012057 (2009)

22. L. L. Niba, M. M. Bokonga, F. L. Jackson, D. S. Schlimme, B. W. Li, J. Food Sci. 67, 1701-1705 (2001)

23. F. Sosulski, E. S. Humbert, K. Bui J. D. Jones, J. Food Sci. 41, 1349-1352 (1976)

24. C. Vidal-Valverde, J. Erias, S. Vulverde, 1992, J. Food Prot. 55,301-304.

25. A. El-Baltegy, Effect of home traditional methods on quality aspect of some legumes (M.Sc. Thesis, Faculty of Agriculture, Minofiya University, Shibin El-Kom, Egypt, 1996).

26. D. L. Rom, J. M. Shull, A. Chandrashekar, A. W. Kirleis, Cereal Chem. 69, 178-181 (1992)

27. M .S. Rahman, T. P. Labuza, Water Activity and Food Preservation (CRC Press, Taylor and Francis Group, New York, 2007)

28. M. B. Go, S. P. Velos, A. V. Minyamin, R. D. Bagsit, R. G. Pableo, Trop. Tech. J. 19, 1-7 (2015)

29. C. Ruiz-Capillas, F. Jiménez-Colmenero, Food Chem. 112, 487-493 (2009)

30. H. S. Lambrecht, Sulfite substitutes for the prevention of enzymatic browning in foods (American Chemical Society, Washington D.C., 1995)

31. K. M. Sahay, K. K. Singh, Unit operations of Agricultural Processing (Vikas Publishing House Pvt. Ltd. New Delhi, 1996)

32. S. Chandra, Samsher, Afr. J. Agric. Res.8, 48494852 (2013)

33. F. Altay, S. Gunaseakran, J. Agric. Food Chem. 54, 4235-4245 (2006)

34. U. Singh, J. Food Sci. Technol. 38,191-199 (2001)

35. P. Housson, G. S. Ayenor, Afr. J. Sci. Technol. 3, 121-126 (2002)

36. E. I. Adeyeye, P. A. Aye, La Vista Italiana Della Sostanze Grasse 1, 253-261 (1998)

37. A. R. Olukemi, O. A. Olayiwola, S. S. Abdulsalam, J. Agric. Sci. 1, 1-5 (2013)

38. M O., Aremu, O. Olaofe, E. T. Akintayo, J. Food Technol. 5, 109-115 (2007)

39. R. Ravi, N. S. Sushelamma, J. Food Sci. 70, S539-S547 (2005)

40. M. Eltayeb, A. Ali, A. Abou-Arab, F. Abu-Salem,
Afr. J. Food Sci. 5, 82-90 (2011)

41. J. E. Kinsella, Crit. Rev. Food Sci. Nutr. 5, 219225 (1976) 